\title{
Autoradiographic Study of the Post-Natal Cerebellar Neurogenesis in the Chick
}

\author{
T. Pessacq, ${ }^{1}$ Lidia Vidal-Rioja ${ }^{1}$ and N. O. Bianchi ${ }^{2}$ \\ Received Febraury 20, 1971
}

The development of autoradiographic techniques using tritiated thymidine $\left({ }^{3} \mathrm{HTdR}\right)$ has made it possible to trace the origin, migration and fate of cerebellar neuroblasts (Altman 1966, Altman and Das 1966, 1967, Fujita 1964, 1967, 1969, Hanaway 1967, 1968, Miale and Sidman 1961 and Uzman 1960). Utilizing this method, Fujita $(1964,1969)$ was able to demonstrate that in the developing chick the earliest neuroblast arise on the fourth day of embryonic life from the matrix layer. Purkinje cells differentiated between the 5th and 6th day and Golgi cells between the 5th and 9th day of incubation from neuroblasts arising from the matrix layer. Later on, most matrix cells changed into glioblasts and the remainder differentiated into ependymal cells. From the 6th until the 9th day of incubation, neuroblasts forming the external granular layer (EGL) were derived from the external matrix cells. Afterwards, these neuroblasts migrated giving rise to microneurones of the molecular layer (ML) and the internal granular layer (IGL).

Postnatal cerebellar neurogenesis has been analyzed in detail in rats, mice and guinea pigs (Fujita 1967, 1969, Altman 1966, 1969, Altman and Das 1966, 1967, Miale and Sidman 1961 and Uzman, 1960). However, as far as we know, no similar studies have been undertaken in avian species. The present work attempts to give some insight into the postnatal neurogenesis of the chick cerebellum.

\section{Material and methods}

A series of 5-day old chicks were injected intracranially with $20 \mu \mathrm{c}$ of ${ }^{3} \mathrm{HTdR}$ (Sp.Act. $6.9 \mathrm{C} / \mathrm{mM}$ ) dissolved in 0.1 of physiological salt solution. Chicks were inoculated through the anterior fontanelle using a $1 / 2$ in. long needle. Postmortem examination of birds showed that in every case the injection had fallen in the cerebllar cisterne. At 1/4, 1, 4, 16 and 24-hour intervals and at 2, 3, 4, 7, 15 and 30 days 3 to 4 animals inoculated at 5 days of age were sacrificed by decapitation. The brain was dissected out, fixed in 3:1 ethanol: acetic acid and histolotically processed. Slides were mounted with AR-10 Kodak stripping film, exposed for 7 days, developed, and stained through the film with Giemsa stain.

In a second series of experiments 1 to 6-day old chicks were injected intracranially with $20 \mathrm{mc}$ of ${ }^{3} \mathrm{HTdR}$ and sacrificed 2, 3 and 4 days after the injection. A total of 15 chicks were analyzed employing the same histological and auto-

1 Comision de Investigacion Cientifica de la Provincia de Buenos Aires, Argentina.

2 Department of Cell Biology, Public Health Science Division, Gulf South Research Institute, U.S.A. 
radiographic procedures described above. In addition, 5-day old chicks were each injected intraperitoneally with $125 \mu \mathrm{c}$ of ${ }^{3} \mathrm{HTdR}$ and sacrificed 1 hour after the injection. The methodology was similar to that described above except that the exposure time for the autoradiograms was 30 days.

\section{Results}

The EGL of the chick cerebellum is formed by 3 to 4 layers of neuroblasts from the time of hatching until 7-10 days of age. From this stage onward the number of cells in the EGL progressively decrease until they almost disappear by 30 days.

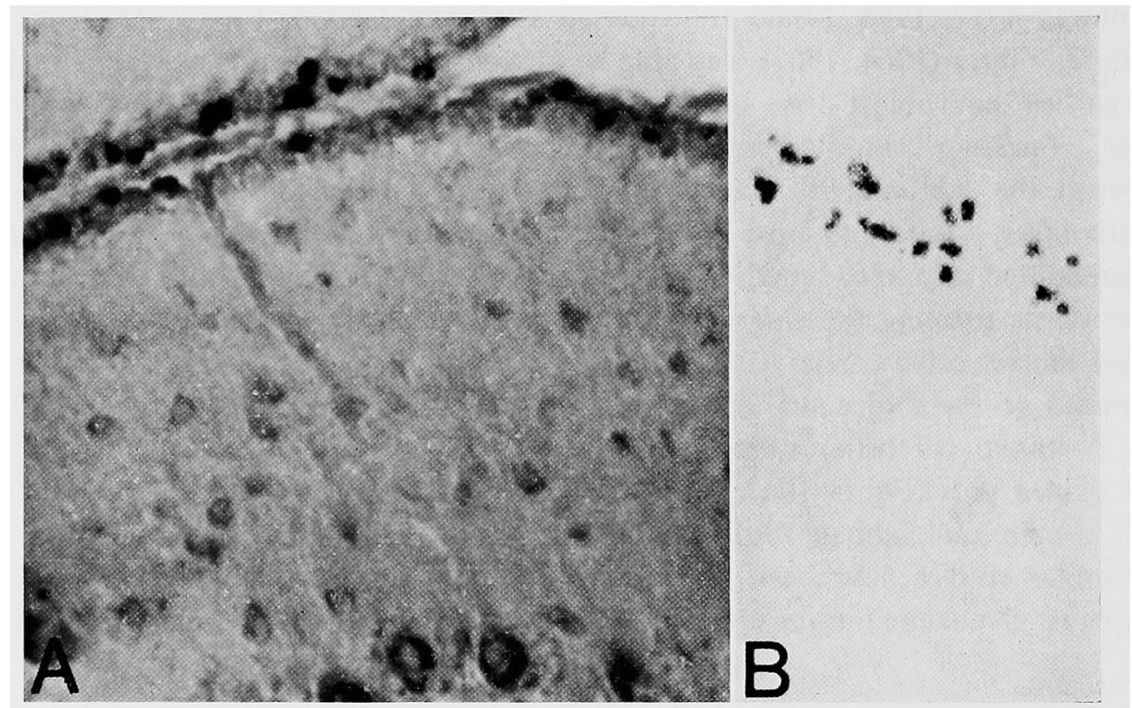

Fig. 1. Cerebellar autoradiogram from a 5-day old chick sacrificed 15 minutes after the intracranial injection of ${ }^{3} \mathrm{HTdR}$. Notice that labeling is restricted to the EGL only. A: Giemsa stained autoradiogram. B: Non-stained autoradiogram. $200 \times$.

In 5-day old chicks sacrificed from 15 minutes up to 2 days after the ${ }^{3} \mathrm{HTdR}$ injection, labeling was circumscribed to 30 to 50 percent of cells in the EGL with only a few neuroblasts showing the beginning of migration through the ML at $24 \mathrm{hrs}$ after labeling (Figs. 1, 2) Thirty-five to 50 percent of cells in the EGL showed silver grains and, interestingly enough, groups of labelled cells could be seen alternating with groups in which no radioactivity was exhibited. Such a phenomenon seems to suggest a certain degree of synchrony in the DNA synthesis among the cells located in the same area.

Between 2 and 3 days after the ${ }^{3} \mathrm{HTdR}$ injection the appearance of tagged cells in the ML and IGL was conspicuous (Fig. 3). The existence of cell division in most of migrating neuroblasts was suggested by the drastic reduction in the number of silver grains in the radioactive cells of the EGL, ML and IGL. However, a certain percentage of cells (10 to 15 percent) were able to migrate without any 
conspicuous dilution of radioactivity (Fig. 2). These observations point out that cell division, at least in some cases, does not necessarily precedes migration. Another interesting finding was that migrating cells were aligned in an orderly manner as though they were following the same pathway on their way through the cerebellar layers (Figs. 3).

Fifteen days after labeling the EGL was considerably thinner while the ML and the IGL increased in their width. In the IGL most cells exhibited silver grain dilution and clear signs of differentiation such as increased size and well depicted

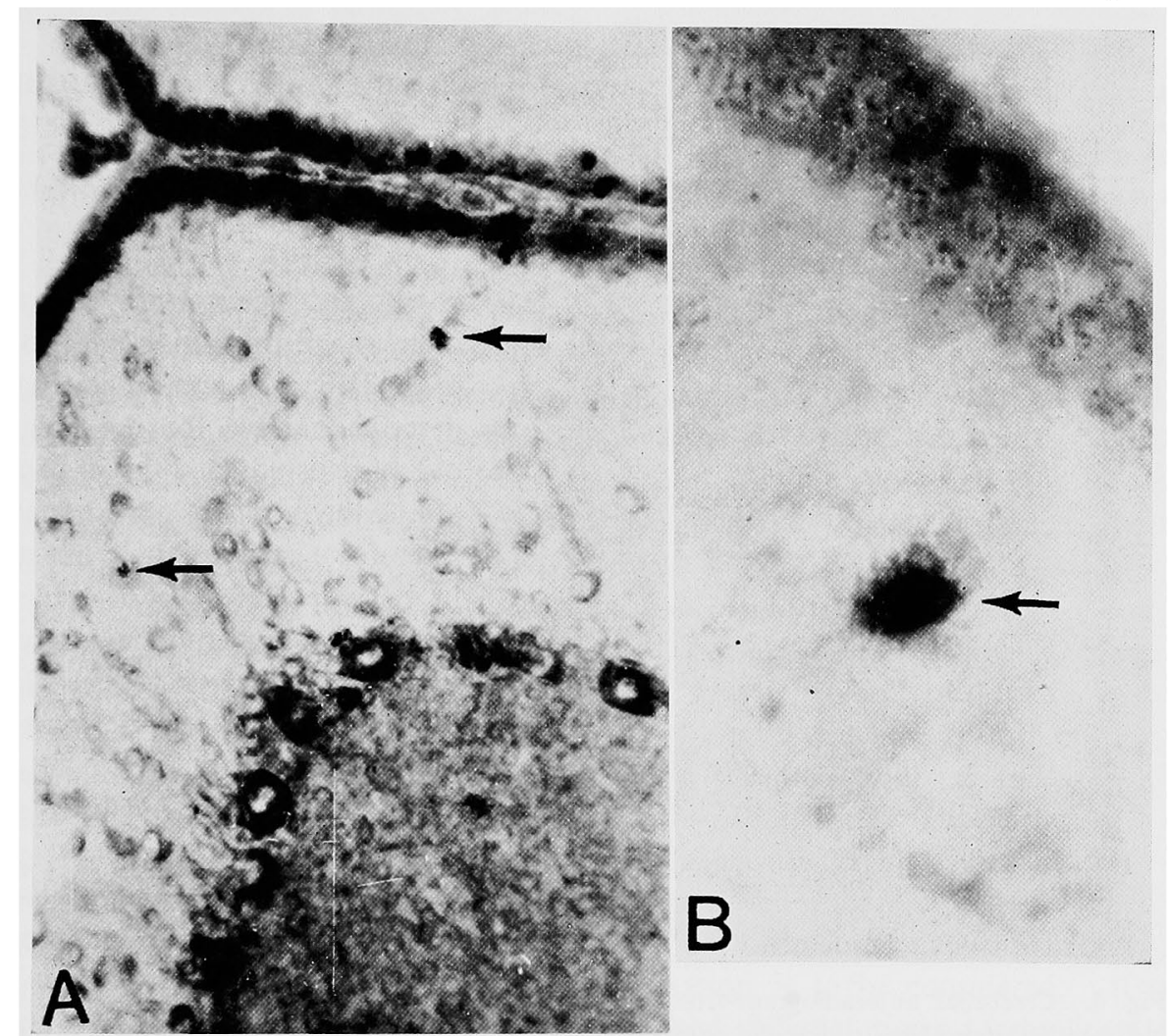

Fig. 2. Cerebellar autoradiogram from a 6-day old chick sacrificed 24 hours after the injection of ${ }^{3} \mathrm{HTdR}$. Notice the labeling in the EGL and some migrating radioactive cells in the ML. (arrows). A: $200 \times$, B: $800 \times$, Giemsa stained.

cytoplasm surrounding the nucleus. However, in the deepest region of the IGL some cells still showed a high degree of radioactivity, probably indicating the absence of division. Moreover, the existence of labelled cells arranged in rows could be observed in the white matter. Since glial cells had a lower silver grain concentration, a previous process of multiplication can be assumed for them.

Thirty days after the ${ }^{3} \mathrm{HTdR}$ injection a slight labeling remained in the IGL only. This conspicuous decrease in the silver grain concentration suggests that cell division continued for at least 1 month after hatching in all cerebellar layers.

The autoradiographic cerebellar pattern observed in 1,2, 3, 4 and 6-day old 

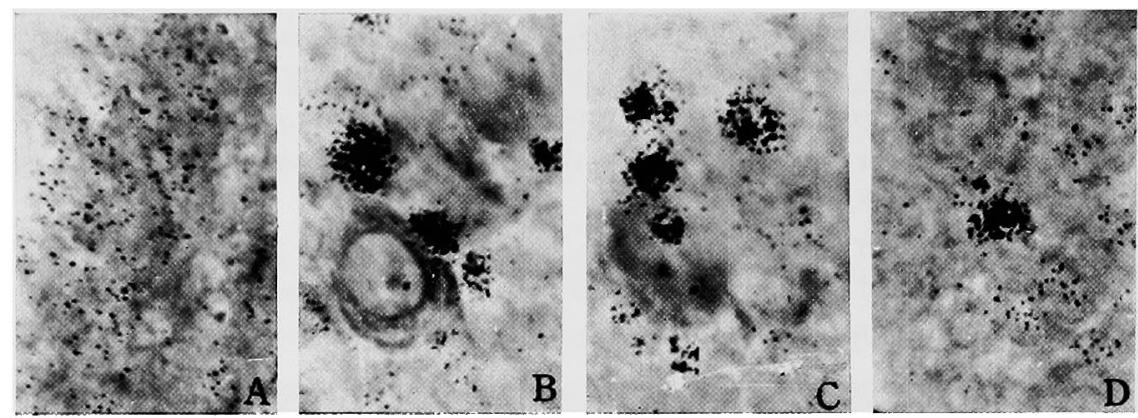

Fig. 3. Different cerebellar areas from a 8-day old chick sacrificed 3 days after the ${ }^{3}$ HTdR injection. A: EGL autoradiogram, notice the remarkable dilution of radioactivity in the labeled cells. B and C: ML and Purkinje cell layer, notice the coexistence of migrating cells with high and low radioactivity. D: IGL, notice a highly radioactive cell surrounded by cells with a remarkable labeling dilution. $800 \times$. Giemsa stain.

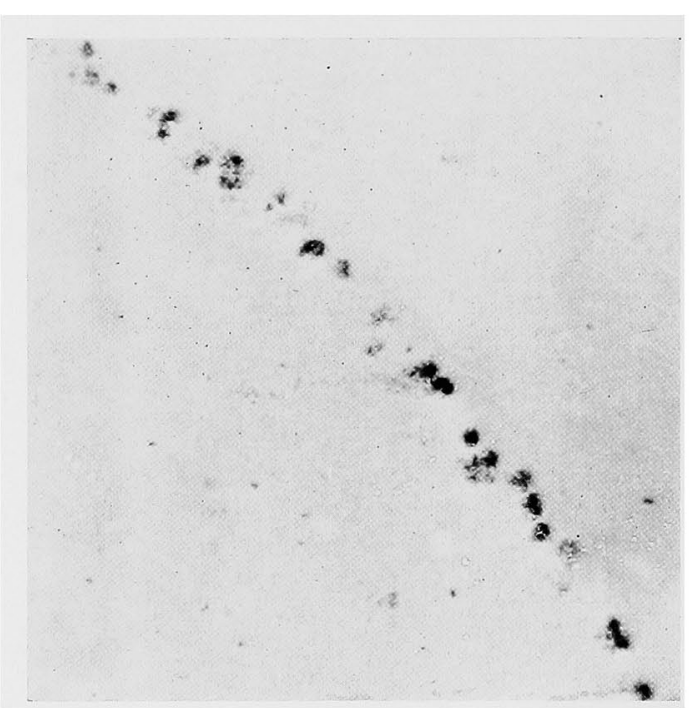

Fig. 4. Cerebellar autoradiogram from a 5-day old chick sacrificed 1 hour after the intraperitoneal injection of ${ }^{3} \mathrm{HTdR}$. The autoradiogram is not stained to stress the location of labeling on the EGL only. $200 \times$.

chicks sacrificed 3 to 4 days after the intracranial injection of ${ }^{3} \mathrm{HTdR}$ was similar to that described above for the 5-day old birds studied 3 to 4 days after the isotope treatment. Therefore, such a pattern seems to be independent of the bird age and consequently dependent of the interval between the ${ }^{3} \mathrm{HTdR}$ injection and the sacrifice of the animal.

Chicks studied 1 hour after the intraperitoneal injection of ${ }^{3} \mathrm{HTdR}$ displayed a cerebellar pattern of labeling similar to that found in birds sacrificed 1 hour after the intracranial treatment (Fig. 4). It is worth mentioning here that other central nervous regions also showed identical patterns of labeling

independently of the mode of injecting the ${ }^{3} \mathrm{HTdR}$.

\section{Discussion}

The results described above clearly indicate that ${ }^{3} \mathrm{HTdR}$ injected either intracranially or intraperitoneally locates in the same regions of the central nervous system. However, the former method seems preferable to the latter since informative autoradiograms are obtained with shorter exposure time and smaller ${ }^{3} \mathrm{HTdR}$ doses. 
Moreover, it has been previously reported, that at least for field-vole bone marrow cells the intraperitoneal injection of ${ }^{3} \mathrm{HTdR}$ represents a pulse labeling lasting no more than 5 to 10 minutes (Bianchi et al. 1969). In the case of cerebellum, chicks sacrificed 1 hour after the intracranial injection of ${ }^{3} \mathrm{HTdR}$ showed a slightly higher concentration of silver grains than those sacrificed 15 minutes after the injection. However, from 1 hour onward, the lengthening of the interval between the injection and sacrifice of the bird apparently did not increase the silver grain concentration or the number of labeled cells. Consequently, it seems justified to conclude that the intracraneal injection of ${ }^{3} \mathrm{HTdR}$ represents a 1 hour (or shorter) pulse treatment.

After hatching, active DNA synthesis in the chick cerebellum seems to be almost exclusively restricted to the EGL. The main support for this assumption comes from the fact that in 5-day old chicks sacrificed at intervals shorter than two days after labeling most of the radioactive cells were located in the EGL.

In the first week after hatching, independent of the animal's age, each 2 or 3 days after the ${ }^{3} \mathrm{HTdR}$ injection a massive migration of cells from the EGL to deeper cerebellar layers could be observed. Therefore, for the EG-cells to migrate a 2 to 3 days stay in the EGL seems to be necessary. In this premigratory period, cells are probably dividing as clearly pointed out by the drastic reduction of radioactivity in migrating and EG-cells. However, since 10 to 15 percent of labeled cells are able to reach their final destiny without any apparent reduction of silver grains, cells division at least in certain cases, seems not to be indispensable for migration.

As suggested by cerebellar labeling patterns of birds surviving for 1 to 2 weeks after ${ }^{3} \mathrm{HTdR}$ treatments, the fate of migrating cells is to give rise to neurons of the ML, IGL (probably basket and stellate cells) and to glial cells of the white matter. Moreover, the drastic decrease of labeling in the cerebellum of 30-day old chicks indicates that cell division still continues after the migration has finished. This fact poses a very interesting question: Why, if DNA synthesis is occurring in all cerebellar layers are only the EG-cells able to become labeled after the ${ }^{3} \mathrm{HTdR}$ injection? Labeling patterns after intraperitoneal injections allow the ruling out of any kind of impairement in ${ }^{3} \mathrm{HTdR}$ diffusion when intracranial injections are employed. Consequently some other explanation is to be considered. If two cell populations pulse labeled with ${ }^{3} \mathrm{HTdR}$ need different times to duplicate the same amount of DNA, the one with the longest DNA synthesis period will be less radioactive than the other. Thus, if this period is too long, autoradiographic methods will not be sensitive enough to detect radioactivity on the nucleus. Accordingly, the lack of radioactivity in neuroblasts other than those in the EGL can be explained by assuming a longer DNA synthesis period for these cells.

It has been suggested that in mammal species somatically and behaviorally mature at birth, postnatal neurogenesis is proportionally less pronounced than in immature (altricious) species. Our observations and the experiments from Fujita (1969) seem to support this view for birds as well. In the chick, a precocious species, most cerebellar neurogenesis occurs during the embryonic life. After hatching, only a small fraction of the cerebellar granular cells is formed and the EGL is dissolved within about 30 days of age. 


\section{Summary}

The kinetics of postnatal cerebellar neurogenesis in chicks was studied by ${ }^{3} \mathrm{HTdR}$ autoradiography. Results suggest that DNA synthesis occurs mainly in the external granular layer. After a premigratory period of 2 to 3 days in the external granular layer, cells begin to migrate and give rise to nuerones of the molecular and internal granular layers and to glial cells of the white matter. During the premigratory period most cells from the external granular layer are dividing; however 10 to $15 \%$ of cells seem to be able to migrate without any previous division. In the chick, a precocious species, postnatal cerebellar neurogenesis seem to proceed at a slower rate than in altricial species such as mice and rats.

\section{References}

Altman, J. 1966. Autoradiographic and histological studies of post-natal neurogenesis II. A longitudinal investigation of the kinetics migration and transformation of cells incorporating tritiated thymidine in infants rats, with special reference to post-natal neurogenesis in some brain regions. J. Com. Neurol. 128: 431-474.

- 1969. Autoradiographic and histological studies of post-natal neurogenesis III. Dating the time of production and onset of differentiation of cerebellar microneurons in rats. J. Com. Neurol. 136: 269-294.

- and Das, G. D. 1966. Autoradiographic and histological studies of post-natal neurogenesis I. A longitudinal investigation of the kinetics, migration and transformation of cells incorporating thymidine in neonate rats, with special references to post-natal neurogenesis in some brain regions. J. Com. Neurol. 122: 311-328.

- and - 1967. Postnatal neurogenesis in Guinea pig. Nature 214: 1098-1101.

Bianchi, N. O., Comtreras, J. and Dulout, F. N. 1969. Intraspecies autosomal polymorphism and chromosome replication in Akodon molinae (Rodentia: Cricetidae). Canad. J. Genet. Cytol. 11 : 233-242.

Fujita, S. 1964. Analysis of neuron differentiation in the central nervous system by tritiated thymidine autoradiography. J. Com. Neurol. 122: 311-327.

- 1967. Quantiative analysis of cell proliferation and differentiation in the cortex of the postnatal mouse cerebellum. J. Cell Biol. 32: 277-287.

- 1969. Autoradiographic studies on histogenesis of the cerebellar cortex. 1st. Internat. Symp. on Neurobiology of Cerbellar Evolution and Development. Ed. R. Llinas, AMA pp. $743-747$.

Hanaway, J. 1967. Formation of the external granular layer in the chick cerebellum. 80th Ann. Session Am. Assoc. Anat. Anat. Rec. 157: 255.

- 1968. Origin of the basket cells in the molecular layer of the chick cerebellum. 81st Ann. Session Am. Association Anat. Anat. Rec. 160: 360.

Miale, I. and Sidman, R. L. 1961. An autoradiographic analysis of histogenesis in the mouse cerebellum. Exp. Neurol. 4: 277-296.

Uzman, L. L. 1960. The histogenesis of the mouse cerebellum as studied by its tritiated thymidine uptake. J. Com. Neurol. 114: 137-160. 